\title{
Effective Use of Multimedia Explanations in Open e-Learning Environment Fosters Student Success
}

\author{
Tatiana Tchoubar
}

\begin{abstract}
Multimedia explanations include videos, quizzes, worksheets and animations. During the academic year of 2011/12, a study was conducted at SCC College, NY, US, which demonstrates a positive association between use of multimedia explanations in an open eLearning environment and student success. Computer based visual explanations were developed using online authoring sites and editing software, and published by subject in designated areas of Virtual Learning Commons (VLC), which also provided students with social networking tools. The faculty were creating and discussing their multimedia explanations in a collaborative online environment. Original analytics were written in Java Server Pages and XML programming languages in order to keep confidential statistics on student use. Analysis based on student outcomes has yielded a positive association between use of the VLC and student success. Surveys and data-tracking has enabled the Title III project office to find out what types of multimedia explanations appeal best to students.
\end{abstract}

Index Terms-Analytics, e-learning, multimedia explanations, open environment, student success.

\section{INTRODUCTION}

The cognitive theory of multimedia learning presented by the end of the $20^{\text {th }}$ century [1], was drawn on dual coding theory [2], cognitive load theory [3] and the constructivist theory of learning. It comprises a number of principles referring to combination of text, narration and images for effective instructional design, such as spatial and temporal contiguity, non-redundancy, complementary modality, and coherence. Later works on visualization effectiveness confirmed the importance of cognitive load [4] for optimal instructional design. Some authors considered the impact of learning styles [5], perceptual multimedia quality [6] and emotional atmosphere [7] on effective multimedia learning, but no correlation was found between positive emotion or multimedia quality and learning performance, and a limited correlation was suggested between the matching of web design to the student learning style and his performance. A number of studies concentrated on analysis of Intelligent Tutoring Systems based on ACT theory of cognition [8] and on utilization of adaptive and dynamic web hypermedia [9]. In recent research on multiple representations no quantitative data indicated causation between the presence of multimedia and better learning outcomes [10].

Manuscript received May 25, 2013; revised September 10, 2013. This work was supported in part by the U.S. Department of Education under federal grant CFDA \#84.031A PR/Award \#P031A100077.

Tatiana Tchoubar is with Stony Brook University, Stony Brook, NY 11790, USA (e-mail:Tatiana.tchoubar@gmail.com).

\section{EXPERIMENTAL SETTING}

A federal grant funded study was conducted at the SCCC, the largest community college of the State University of New York (SUNY) system, which has 24,000 students attending three campuses on Long Island.

The grant was intended to increase student engagement in learning, which, according to research, was expected to increase student success [11]. Four groups of faculty were working on enabling electronically enrollment, advising and intervention systems, creating the learning materials to improve twenty Gateway Courses that most students enroll in but many students don't succeed in. It was expected that teaching and learning would be enriched through a college-wide Virtual Learning Commons, by providing a unified web delivery system for on-line and on-site resources. Web-enabled enrollment, virtual orientation and academic support meet the expectations of digital generation students, who have become used to immediate wireless and internet access to resources and services at school [12].

Since SCCC had a relatively undeveloped web presence and did not have more than $20 \%$ of classes web-enabled, it has been a challenge to place educational materials in an online repository open for every college student and faculty member.

The faculty-driven VLC working group had drafted pilot mapping for the VLC. The VLC has been implemented in a portlet environment, Luminis. The web design was scripted in CSS, HTML and JavaScript programming languages.

The VLC was developed as a free-access community space where the students can find online support for every college activity, from enrollment and admission, to studying for their classes. Faculty members involved in teaching the twenty gateway courses, and volunteers, were creating online learning materials for students. Policies for intellectual property agreements and copyrights were created by the faculty union, in negotiation with college administration. Standard policies were being used to get permission to use materials from the web, YouTube, publishers, and Learning Object Repositories. Written policies, credits and contact information were included on the VLC web pages.

According to the Center for Community College Student Engagement [13], students at SCCC were 13\% less likely to work with peers and $50 \%$ less likely to ask a question in class than students at similar colleges nationwide. Accessible college-wide learning materials reinforcing the courses, accompanied by synchronous and asynchronous interaction with the faculty, were expected to improve this situation. 


\section{TeChNOLOGiCAl SOlution}

The VLC was conceived as a free online space for the students to exchange ideas and enrich their learning experience, to communicate with their professors and their peers, and to reinforce their knowledge of the subjects and of the college in general, in order to help them to succeed.

The first group of functionalities allowed for a virtual orientation, with an enrollment and admissions web app and links to college services, the library, and student learning centers. Collaborative tools, such as a group chat, message board, and live file sharing, represent functionalities of the second group. The third and the most important VLC functionality was the database driven learning object repository. An in-house analytics system was built in order to be able to research and report on student use of the VLC learning materials. The VLC was free of assignment. As the assessment was not done by or reported to faculty, the use of the VLC and its impact on grades was not visible to either students or faculty at all.

Faculty and instructional technology staff have spent some time in choosing a platform to host the VLC. The Learning Management System used at SCCC is Desire2Learn (D2L). As mentioned before, only some of the academic offerings at SCCC are web enabled. D2L has a customizable outlook and, like all LMSs, it is designed for course deposit: it features analytics for faculty use, a searchable learning object repository, and the MEs in it are shareable, scoreable and reusable. The SCCC Content Management System (CMS), Luminis, had the advantage to be open to the whole college community - students as well as faculty. That is why Luminis-based portal was chosen to host the VLC. Like the LMS, the portal was protected by an authentication process (Fig. 1).

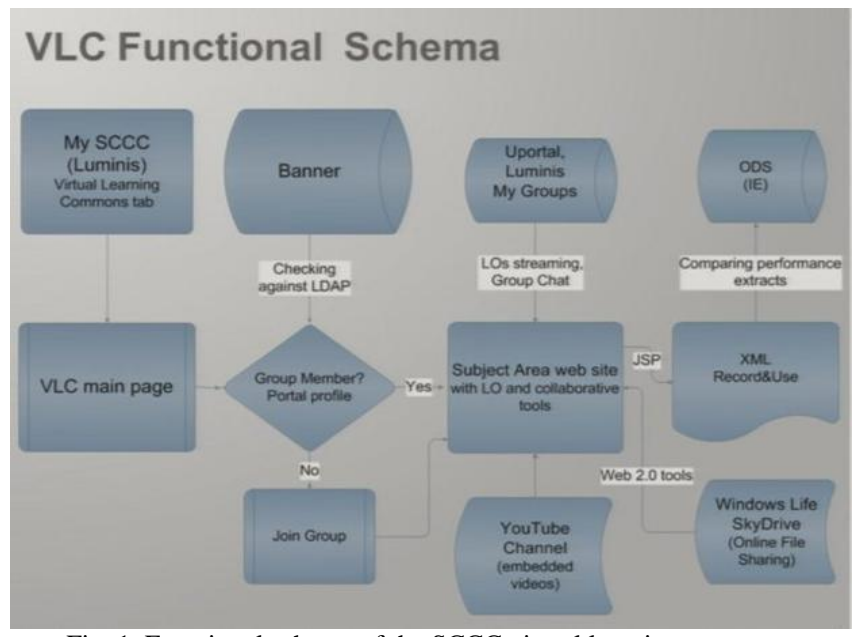

Fig. 1. Functional schema of the SCCC virtual learning commons.

On the discipline-area pages, students were able to find links to the ME, stored in the Luminis My Groups File Sharing Uportal database, and My Groups collaborative tools, such as Group Chat and Message Board. Live File Sharing was been connected from the Windows Live Sky Drive. Longer videos which require more server space were stored in the college's YouTube channel (Fig. 1).

Each discipline-area's page has been scripted incorporating in-house analytics in JSP, Java Server Pages, giving an XML file containing the user and ME data. The
XML file was being compared to the student performance data from the ODS, Operational Data Store, in order to obtain the results of the impact of the VLC on student retention, persistence, academic success, and satisfaction. The VLC analytics were totally confidential: particular student information was never disclosed, because it was retrieved and treated by a software that provides only the output of general statistical numbers. The purpose of the analytics was to find out which categories of students were accessing the VLC, with an emphasis on first time, full time students, and whether the use of VLC improved their persistence and success.

The main VLC page was intended to have a very simple, straightforward design, with few direct links. Students were greeted on the opening page with an Xtranormal cartoon serial with episodes based on characters who were discovering the VLC for themselves. Yellow buttons in the middle of the page are the entry points to the six online learning areas of gateway courses, containing $350 \mathrm{ME}$. Those areas were Biology, Freshman Seminar, Communication, Mathematics, Psychology and Reading.

When the students entered the learning area, for example the Mathematics area, they had access to three types of learning objects: worksheets, videos and interactive exercises (self-quizzes in this particular case) (Fig. 2). Mathematics pages also have a dictionary for terminology, which is a basic lexicon that provides pop-ups of the mathematics terms used in the multimedia explanations.

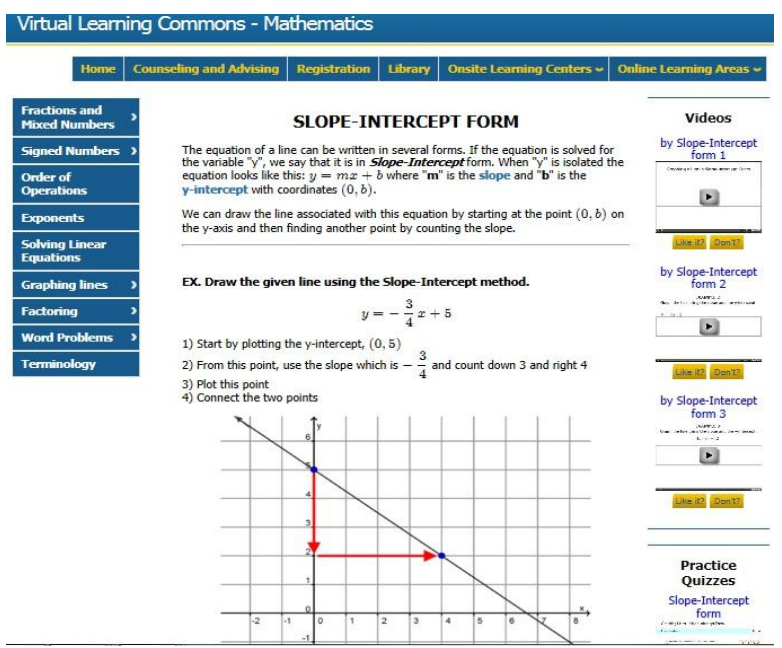

Fig. 2. Online learning area outlook (mathematics).

Quizzes were made using Wondershare Quiz Creator. Various formats were being used for interactive exercises, such as drag-and-drops, fill-in exercises, crosswords and online forms. Some faculty in the Liberal Arts areas were creating animations using Go!Animate, Xtranormal and Voki, the Avatar web program. Some videos in the learning areas were shot with video and audio equipment. However, most educational videos in the VLC were PowerPoint slideshows, recorded with Camtasia screen shooting and video editing software for education, which allows faculty to easily add soundtracks, captions, call-outs, transitions and other effects designed to make videos more engaging.

Faculty were creating and discussing the ME using a collaborative online environment of Luminis called "My Groups". Here, each subject area had its own My Group, 
permitting faculty within the group to upload files and post links. My Groups has an asynchronous message board as well as a synchronous group chat.

In addition to the analytics designed to capture which students access the VLC, another assessment tool has been added, wherein students can click "Like It?" or "Don't Like It?" buttons below each ME. VLC analytics were built in such a manner as to avoid disclosing student information: the associations were done by the software, and the research results yields total numbers of students, as per the college's internal protocols. The analytics did allow us to research associations between different combinations of student characteristics and ME parameters, automatically interfacing those with the student performance records coming from the Banner ODS.

\section{RESEARCH}

The two studies we have done so far were aimed at discovering how to encourage the students to use the Virtual Learning Commons (VLC) and to assess the outcomes of the students using the VLC. A research was done with a purpose to determine the best motivation for students to use the VLC. Guided by motivational design [14], students were assigned to an Extra Credit Group, Reading a Memo Group and one control group. These groups differed in how much information students were given about the VLC and how relevant they felt the VLC was. ANOVA test was done to compare the percentage of VLC users in the groups and their outcomes.

The first study was conducted during the fall semester of 2011, tracking only the first- year full-time students in five gateway courses: two College Seminar courses and three Mathematics courses (COL101, COL105, MAT001, MAT006, MAT007). The only students who had access to the VLC were those enrolled in these five courses at the college. The participants of the study were randomly assigned to three groups. The first group of students $(n=365)$ were given an extra-credit treatment, in which they would be given an extra credit for using the VLC. The second group of students $(n=381)$ received a different treatment: a standard memo was read to them by their instructor. The memo described what the VLC is and where to find it. The control group of students $(n=6653)$ were not given any formal information in their classrooms about the VLC.

The research question of the first study was whether the difference in the percentage of the students using the VLC was significant enough to say which of the three treatments was more effective. The null hypothesis was that there was no significant difference between percentages of student users under each treatment.

Predictably enough, the percentage of the extra-credit treatment group students using the VLC was the highest of the three groups. The group that had the memo read to them had the second highest percentage of VLC users, and the group that received no instruction on the VLC had the lowest percentage of VLC users.

An Anova \& Tukey HSD analysis was performed with SPSS software. The analysis result allowed us to reject null hypothesis. We found out that giving extra credit can be an effective way to encourage students to use the VLC. However, even if the "reading a memo" group had a slightly higher percentage of student VLC users, the difference was not significant enough to say that reading a memo was an effective way to encourage students to use the VLC (extra credit/reading memo: sig 0.000; extra credit/no treatment: sig 0.000 ; reading a memo/no treatment: sig 0.746). Based on this research, faculty members were encouraged to incorporate the VLC in their courses.

The second study was aimed to see if using the VLC could improve student outcomes. A preliminary analysis was needed to determine whether the extra credit treatment had influenced the research. As indicated by the first study, some students were given extra credit for using the VLC. Thus, the outcomes of these students were manipulated in some way. A chi-square analysis was done to test the impact of "extra credit" upon the student outcomes. The null hypothesis was that there is no association between treatment of extra credit and student outcomes. Rejecting the null hypothesis, the result showed that there was an association between extra credit treatment and student outcomes ( $\mathrm{X}^{2}$ 8.087a, p 0.018). Therefore, we excluded the extra credit group from the second study.

9365 grades remained after we excluded the grades from the extra credit group. These grades were coded into two groups: PASS and FAIL. The variables after coding were: 1) If student uses VLC: Yes/No and 2) Student outcomes: Pass (A, B+, B, C+, C, S, SA, SB, SC)/ Fail (D, F, INC, R, U, W). A chi-square test was performed to determine the associations between the two variables. The null hypothesis was that there was no association between the use of VLC and student outcomes. The result rejected the null hypothesis and showed a significant association between the use of the VLC and student outcomes ( $\mathrm{X}^{2} 5.319^{2}, \mathrm{p}$ 0.021).

Although this finding was encouraging, more analysis needed to be done before we came to the final conclusion about our study. The students' academic performance may be a confounding factor correlating with both the dependent variable "student outcomes" and the independent variable "use of the VLC". In other words, a student who excels in academics tends to be self-motivated and uses the VLC; at the same time, this student is more likely to have better grades.

Based on the availability of data, we used the developmental status of a student to describe this confounding variable. Now the study had two covariates as independent variables: the grade being from a student with developmental hold (DV) (Yes/No) and a student being used VLC (Yes/No), dependent variable being student outcomes (Pass/Fail). A logistic regression was done to test the association between the covariates and the dependent variable (if $\mathrm{DV}, \mathrm{p}=0.00$; if use VLC, $\mathrm{p}=0.023$ ). Variable 1 (if the student had a DV) had a stronger impact on the outcomes. But variable 2 (if the student uses VLC) was still a predictor for student outcomes.

To confirm the results above, a method of stratification was also adopted to control the confounder. Students were stratified into two groups. Group 1 consisted of students with a developmental hold; Group 2 included students without a developmental hold. A statistically significant association 
between the use of VLC and student outcomes was found in both stratification groups. (Group 1: $\mathrm{X}^{2} 14.558^{2}$, p 0.000; Group 2: $\left.\mathrm{X}^{2} 8.057^{2}, \mathrm{p} 0.005\right)$. This result showed that the VLC could be one of the factors promoting student academic performance.

Analytics of hit counts on the learning materials and on "Like it?" and "Don't like it?" buttons, by the type of multimedia explanation (ME), has shown as well that $\mathrm{ME}$ type preferred by students is video, followed by interactive activity, with the written component coming in last place. With this information, the VLC Team decided, with the help of the Title III office and other college personnel to make more efforts to encourage students to use the VLC.

\section{CONCLUSION}

242 faculty and staff have been involved in a federal grant initiative at SCC College, NY, US.

Multimedia explanations including video, quizzes, worksheets and animations were created and published by subject in designated areas of the VLC. Some faculty used the ME in class, while others recommended the VLC for independent study. The VLC also provided students with social networking tools: discussion groups featuring chat, message boards and file sharing.

VLC has been implemented in a portlet environment of the Luminis platform, dynamically connected to the Uportal HSQL database. The web design was scripted in CSS, HTML and JavaScript programming languages. An in-house analytics system created in Java Server Pages and XML languages, allowed keeping confidential statistics on student use. The baseline database was built upon data pulled from the Operational Data Store, connected to the Banner Student Information System. In addition to the analytics designed to capture students' utilization of the VLC, an assessment tool of students' satisfaction with the VLC materials has been added, wherein students were given a choice to click "Like It?" or "Don't Like It?" buttons below each multimedia explanation. Statistical analysis was done using ANOVA and Tukey HSD methods on SPSS software.

Nonequivalent group experimental research design analysis, based on data of about 7044 student outcomes and student use of the VLC, yielded a positive association between use of the VLC and student success. Using a motivational model of instructional design, a study aimed to discover how to encourage students to use the VLC, demonstrated statistically significant effectiveness of offering extra credit for VLC use. Surveys and data-tracking allowed determining what types of multimedia explanations appeal best to students.

Based on the study, it is recommended that instructors diversify and expand multimedia explanations that the students find useful, and coordinate a web presence for virtual orientation, online advising and tutoring.

\section{ACKNOWLEDGMENT}

T. Tchoubar thanks her former colleagues at SCC College, participated in the federal grant initiative during 2011/12 academic year: VLC team of 54 members, a Gateway Course Support Enhancement team of 63 members, a Task Force, a Steering Committee, and the grant office staff.

\section{REFERENCES}

[1] R. Moreno and R. E. Mayer, "A learner-centered approach to multimedia explanations: Deriving instructional design principles from cognitive theory," Interactive multimedia electronic journal of computer-enhanced learning, vol. 2, no. 2, pp. 12-20, 2000.

[2] A. Paivio, Mental representation: A dual coding approach, Oxford, England: Oxford University Press, 1986.

[3] J. Sweller, "Cognitive load during problem solving: Effects on learning," Cognitive Science, vol. 12, pp. 257-285, 1988.

[4] E. W. Anderson, K. C. Potter, L. E. Matzen, J. F. Shepherd, G. A. Preston, and C. T. Silva, "A user study of visualization effectiveness using EEG and cognitive load," Computer Graphics Forum, vol. 30, no. 3, pp. 791-800, Blackwell Publishing Ltd., 2011.

[5] P. Germanakos, N. Tsianos, Z. Lekkas, C. Mourlas, and G. Samaras, "Capturing essential intrinsic user behaviour values for the design of comprehensive web-based personalized environments," Computers in Human Behavior, vol. 24, no. 4, pp. 1434-1451, 2008.

[6] S. R. Gulliver and G. Ghinea, "Stars in their eyes: What eye-tracking reveals about multimedia perceptual quality," IEEE Transactions on Systems, Man and Cybernetics, Part A: Systems and Humans, vol. 34, no. 4, pp. 472-482, 2004

[7] C. M. Chen and Y. C. Sun, "Assessing the effects of different multimedia materials on emotions and learning performance for visual and verbal style learners," Computers \& Education, 2012.

[8] J. R. Anderson, M. Matessa, and C. Lebiere, "ACT-R: A theory of higher level cognition and its relation to visual attention," Human-Computer Interaction, vol. 12, no. 4, pp. 439-462, 1997.

[9] P. Brusilovsky, "Adaptive hypermedia," User modeling and user-adapted interaction, vol. 11, no. 1-2, pp. 87-110, 2011.

[10] M. D. Sankey, D. Birch, and M. W. Gardiner, "The impact of multiple representations of content using multimedia on learning outcomes across learning styles and modal preferences," International Journal of Education and Development using Information and Communication Technology (IJEDICT), vol. 7, issue 3, pp. 18-35, 2011.

[11] E. T. Pascarella and P. T. Terenzini, How College Affects Students, A Third Decade of Research, San Francisco, CA: Jossey-Bass, vol. 2, 2005.

[12] N. G. Barnes and E. Mattson, "Social media in the 2009 inc. 500: new tools and new trends," Journal of New Communications Research, vol. 4, no. 2, pp. 70-79, 2009.

[13] Center for Community College Student Engagement. (2009). [Online]. Available: http://www.ccsse.org/sense/survey/comparison.cfm

[14] J. M. Keller, "Motivational design of instruction. Instructional Design Theories and Instruction: An Overview of Their Current Status," pp. 383-429, 1983.

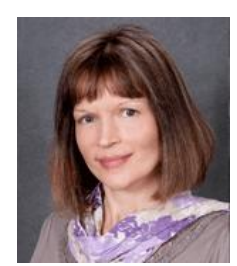

Tatiana Tchoubar holds a master degree from Sorbonne Nouvelle - Paris III University, France, in Online Instructional Design, 2008. In 2010 she was admitted in Ph.D. program at Technology and Society Department of Stony Brook University, College of Engineering, with concentration in Educational Technologies.

Tatiana is a lecturer at the Department of Technology and Society, Stony Brook University, NY, USA. In 2011/12 Tatiana worked as a Faculty/Instructional Technologist/Webmaster at SCC College, NY, USA. At Distance Learning Department of Sorbonne Nouvelle, she was tutoring online courses on various Learning Management Systems, such as Blackboard, WebCT and Moodle. Tatiana's publications and research interests are in the field of E-learning, knowledge processing, multimedia explanations, learning objects, online environments, and educational technology.

Prof. Tchoubar is a member of such professional organizations as ACTFL, International Society for Technology in Education, eLearning Francophone, eLearning 2.0, alumni network of Sorbonne University. She was awarded a 2006 Prize of Sorbonne University, Paris, France. She served at numerous committees, including SCC College grant task force and steering committee. 